\title{
Application of chimerical ALT perforator flap with vastus lateralis muscle mass for the reconstruction of oral and submandibular defects after radical resection of tongue carcinoma: a retrospective cohort study
}

Rong Yang, Xiaoshan Wu, Pathak Ajit Kumar, Yafei Xiong, Canhua Jiang, Xinchun Jian and Feng Guo*

\begin{abstract}
Background: Patients with tongue carcinoma who undergo combined tongue and neck radical resection often have simultaneous oral and submandibular defects. Due to its high flexibility, the anterolateral thigh (ALT) perforator flap is gradually being adopted by surgeons for oral reconstruction. However, the tissue volume of perforator flaps is insufficient for the reconstruction of both the oral and submandibular regions. In this retrospective cohort study, we compared the postoperative outcomes and complications between patients reconstructed with using the classical ALT perforator flap and patients reconstructed using the chimeric ALT perforator flap with vastus lateralis muscle mass.
\end{abstract}

Methods: From August 2017 to August 2019, 25 patients underwent reconstructive therapy using a classical ALT perforator flap (classical group), while 26 patients were reconstructed with the chimeric ALT perforator flap (chimeric group) after radical resection of tongue cancer in Xiangya Hospital, Central South University. The flap survival rate, incidence of submandibular infection, lateral appearance, lower extremity function, and quality of life were compared between the two groups.

Results: There were no differences in flap survival rate and postoperative lower extremity function between the two groups. The incidence of submandibular infection was 15.4 and $40 \%$ in the chimeric and classical group, respectively. The duration of recovery was $12.20 \pm 2.69$ and $15.67 \pm 4.09$ days in the chimeric and classical group, respectively. The submandibular region fullness was satisfactory in the chimeric group. The postoperative quality of life in the chimeric group was better than that in the classical group $(P<0.05)$.

Conclusions: The chimerical ALT perforator flap with muscle mass reconstructs both the oral and submandibular defects accurately. It maintains the profile and fullness of the submandibular region and may reduce the incidence of submandibular infection.

Keywords: Tongue malignant tumor, Reconstruction, Perforator flap, Chimeric flap

\footnotetext{
* Correspondence: dentguo@126.com

Department of Oral and Maxillofacial Surgery, Xiangya Hospital, Central

South University, Changsha 410008, Hunan province, China
}

(c) The Author(s). 2020 Open Access This article is licensed under a Creative Commons Attribution 4.0 International License, which permits use, sharing, adaptation, distribution and reproduction in any medium or format, as long as you give appropriate credit to the original author(s) and the source, provide a link to the Creative Commons licence, and indicate if changes were made. The images or other third party material in this article are included in the article's Creative Commons licence, unless indicated otherwise in a credit line to the material. If material is not included in the article's Creative Commons licence and your intended use is not permitted by statutory regulation or exceeds the permitted use, you will need to obtain permission directly from the copyright holder. To view a copy of this licence, visit http://creativecommons.org/licenses/by/4.0/ The Creative Commons Public Domain Dedication waiver (http://creativecommons.org/publicdomain/zero/1.0/) applies to the data made available in this article, unless otherwise stated in a credit line to the data. 


\section{Background}

Oral squamous cell carcinoma (OSCC) is one of the most common malignant tumors in the body, with tongue cancer as the most frequently observed type of OSCC. It has been reported that the 5-year survival rate of tongue cancer is about $60 \%$. The incidence rates of mortality and recurrence have increased in recent years due to local recurrence and submandibular cervical lymph node metastasis [1-3]. Therefore, it is an important challenge for surgeons to develop reasonable surgical treatment strategies, including therapeutic resection, postoperative defect reconstruction, and functional restoration.

Treatment with surgical resection, adjuvant radiotherapy, and chemotherapy are the main therapeutic strategies for the tongue carcinoma. The purpose of surgical treatment is to excise the primary tumor with a wide margin. The tongue is a complex organ which is composed of striated muscles. The tumor cells often migrate from the primary site, infiltrate into the muscle, and develop into local recurrences in the mouth floor and submandibular region. Because of the special anatomical features of the tongue, patients with tongue carcinoma often experience early lymph node metastasis [4-6]. Therefore, the thoroughness of the resection in the case of tongue cancer is of particularly importance. It has been recently suggested that the upper lingual muscle groups, such as the genioglossus muscle, geniohyoid muscle, mylohyoid muscle, and/or anterior belly of digastric muscle should also be resected in the radical resection to reduce the possibility of recurrence $[5,7,8]$. However, defects in the mouth floor and submandibular region post-operation result in the creation of a large unused space, leading to complications such as submandibular wound infection and oral fistula, thereby prolonging the recovery period of the patients and seriously affecting their prognosis $[7,9]$.

It is challenging to reconstruct the oral and submandibular defects simultaneously $[10,11]$. In recent decades, free anterolateral thigh flap (ALT) has become one of the main choices for reconstruction due to its high reliability and versatility [11]. The traditional ALT carries redundant subcutaneous tissue, fascia lata, and muscle, with a high volume of tissue volume that is far beyond the needs of the surgery. As a result, the perforator ALT flap was developed. The vascular pedicle was skeletonized to obtain the ideal length and to avoid the use of redundant amounts of tissue, which allowed for the accurate repair of the primary oral defect [12-15]. However, the defect of submandibular region is left unfilled, which may lead to the infection and depression of the submandibular region. To address these shortcomings, the perforator-based chimeric flap with a muscle component has been applied in the reconstruction of complex extremity defects [16]. However, it has not yet been used for the reconstruction of both the oral and submandibular defects after radical resection of tongue cancer.

In this retrospective cohort study, the flap survival rate, the duration of flap harvesting, the incidence of submandibular infection, and lateral appearance were compared between two groups treated with different reconstruction methods. The first group underwent reconstructive therapy with a classical perforator ALT flap, while the other group underwent reconstructive therapy with the chimeric perforator ALT flap, with the muscle mass at the end of the descending branch of the lateral circumflex femoral artery (LCFA).

\section{Methods}

\section{Study population}

A total of 51 patients with primary tongue carcinoma who had previously undergone extensive surgical resection in the Department of Oral and Maxillofacial Surgery, Xiangya Hospital of Central South University between August 2017 and August 2019 were enrolled in this retrospective study. All patients had undergone radical tumor resection. The genioglossus muscle, geniohyoid muscle, mylohyoid muscle, and anterior belly of the digastric muscle were resected for all patients due to aggressive tumor invasion. The Medical Ethics Committee of Xiangya Hospital, Central South University approved this study. The patient's identity was preserved.

Demographic information on the patients, including age, sex, tumor stage, pathological $\mathrm{T}$ or $\mathrm{N}$ status, size of dead cavity, and size of flap, were collected and analyzed [17]. The inclusion criteria were as follows: (1) previously untreated oral cancer; (2) pathologically proven as squamous cell carcinoma of tongue by biopsy before surgery; (3) reconstruction with ALT perforator flap or ALT chimeric flap. The exclusion criteria included: (1) history of previous craniofacial surgery; (2) distant metastasis or contraindication for curative surgery; (3) the postoperative follow-up data were incomplete or lost; (4) patients who received radiotherapy, chemotherapy, and other treatment before operation.

Among these patients, 25 cases underwent reconstructive therapy using the classical ALT perforator (classical group), while 26 cases underwent reconstructive therapy using the chimerical ALT perforator flap with a mass of vastus lateralis muscle on the distal runoff of the lateral circumflex femoral artery (chimeric group). For all cases, the resection of the primary sites and reconstruction were performed by one surgeon (Dr. Feng Guo) and his team. All of the cases underwent wound recovery assessment and management during the period between the date of surgery and the date of wound healing. The follow-up duration was 6 to 24 months. 


\section{Harvesting of the classical and chimerical ALT perforator flap}

For the harvesting of the classical ALT perforator flap, we used a previously described method [18]. Briefly, doppler ultrasonography was used to map the perforator in the anterolateral thigh region prior to surgery. After radical resection, we dissected the pre-positioned perforator to the descending branch of the LCFA retrogradely without destroying the integrity of the fascia lata (Fig. 1a).

For the chimeric flap, the vastus lateralis muscle corresponding to the size of the dead space was harvested at the distal end of the descending branch of the LCFA. The vessel distance between the distal end of muscle mass and the perforator branch was determined by the distance between the defect of oral mucosa and the submandibular dead space (Fig. 1b). In the reconstruction, the flap was used to repair the defect of oral cavity, and the muscle mass was used to repair the submandibular dead space (Fig. 2).

In this study, free flap failure was defined when the flap was completely or partially lost, that is when a large enough area of the flap was lost that prevented obtaining the intended functional results [19].

\section{Assessment of donor site function and quality of life}

The Lower Extremity Functional Scale (LEFS) was used to assess the donor site function [20]. It contains 20 items, each of which is rated on a 5-point scale, from 0 (extreme difficulty or unable to perform) to 4 (no difficulty). The 20 items are listed in the Additional file 1.

The University of Washington Quality of Life Scale (UW-QoL, Version 4) was used to record health-related quality of life in patients with head and neck cancer. It contains 12 questions referring to pain, appearance, activity, recreation, swallowing, chewing, speech, shoulder function, taste, saliva, mood, and anxiety. The answer to each question is scored from 0 to 100 [21]. Detailed information on the UW-QoL is provided in Additional file 2.

\section{Data collection and analysis}

Surgical parameters, including the duration of harvesting flap, the survival rate of the flap, the incidence of submandibular infection, and the duration of recovery, were collected. The function of the donor area, the appearance of the submandibular region, and the quality of life were recorded and analyzed after patient recovery. Data were compared between the two groups using Fisher's accurate test and unpaired Student's $t$-test (SPSS 22.0). $P<0.05$ was considered statistically significant.

\section{Results}

\section{Patient demographics}

The mean age of the chimeric flap group was $51.73 \pm$ 8.42 years, and the classical ALT flap group was $48.41 \pm$ 7.83 years. The clinical stages and the metastasis of lymph nodes were compared between two groups, and no statistically significant difference was found (Table 1 ).

\section{Flap harvesting time and survival rate}

The flap harvesting time was $99.12 \pm 28.30 \mathrm{~min}$ in the chimeric group, and $96.71 \pm 20.64 \mathrm{~min}$ in the classical group. There was no significant difference between the two groups $(P=0.92)$. The success rate of the flap was $100 \%$ in the chimeric group, and $92 \%$ in the classical group. A partial loss of the flap was observed in two patients in the classical group. There was no significant difference between the groups $(P=0.98)$ (Table 2$)$.
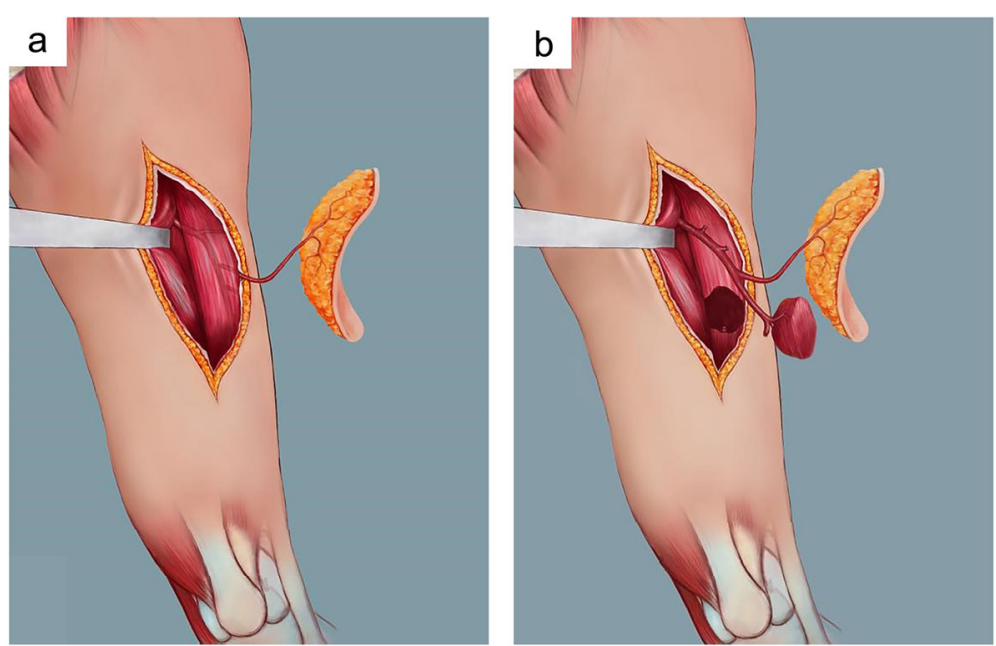

Fig. 1 Schematic representation of the chimeric and classical ALT flaps. a Classical ALT perforator flap of descending branch of lateral circumflex femoral artery. $\mathbf{b}$ Chimeric ALT flap with vastus lateralis muscle mass 

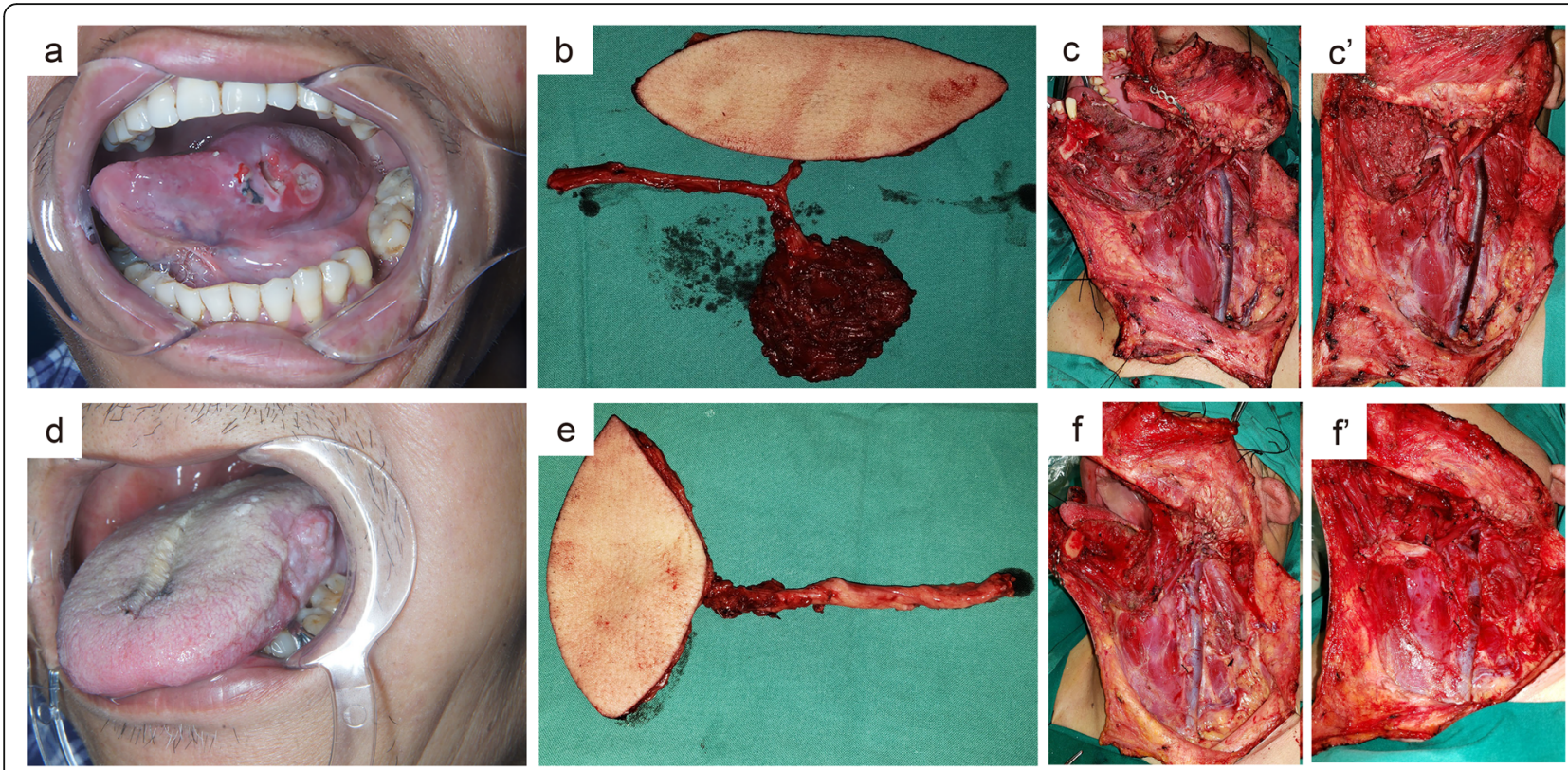

Fig. 2 Comparison of the reconstruction of oral and submandibular defects using the two types of flaps. a-c. Reconstruction of oral and submandibular defects using the chimeric ALT flap: (a) the size and location of primary tumor; (b) the chimeric ALT perforator flap; (c, $\mathbf{c}^{\prime}$ ) oral and submandibular defects before and after transplantation with the chimeric ALT perforator flap. $\mathbf{d}$-f. Reconstruction of the oral and submandibular defects using the classical ALT flap: (d) the size and location of the primary tumor; (e) the classical ALT perforator flap; (f, $\left.\mathbf{f}^{\prime}\right)$ oral and submandibular defects before and after transplantation with the classical ALT perforator flap

Table 1 Characteristics of the patients reconstructed with chimeric flap and classical flap

\begin{tabular}{|c|c|c|c|}
\hline \multirow[t]{2}{*}{ Characteristic } & \multicolumn{2}{|l|}{ Flap } & \multirow[t]{2}{*}{$P$} \\
\hline & $\begin{array}{l}\text { Chimeric flap } \\
(n=26)\end{array}$ & $\begin{array}{l}\text { Classical flap } \\
(n=25)\end{array}$ & \\
\hline Age, years (mean $\pm S D$ ) & $51.73 \pm 8.42$ & $48.24 \pm 7.83$ & 0.14 \\
\hline Sex, male: female, n: $\mathrm{n}$ & $25: 1$ & $24: 1$ & 0.98 \\
\hline Tumor stage & & & 0.42 \\
\hline $\mathrm{T} 1$ & 4 & 6 & \\
\hline $\mathrm{T} 2$ & 20 & 16 & \\
\hline T3 & 1 & 3 & \\
\hline T4 & 1 & 0 & \\
\hline Nodal stage & & & 0.54 \\
\hline No & 16 & 13 & \\
\hline N1 & 6 & 4 & \\
\hline N2 & 2 & 5 & \\
\hline N3 & 2 & 3 & \\
\hline Clinical stage & & & 0.78 \\
\hline I & 4 & 3 & \\
\hline$\|$ & 11 & 9 & \\
\hline III & 6 & 5 & \\
\hline IV & 5 & 8 & \\
\hline Size of flap (range) & $8 \mathrm{~cm} \times 4.5 \mathrm{~cm}-14 \mathrm{~cm} \times 6 \mathrm{~cm}$ & $7 \mathrm{~cm} \times 4 \mathrm{~cm}-14 \mathrm{~cm} \times 7 \mathrm{~cm}$ & 0.60 \\
\hline Size of muscle (range) & $3 \mathrm{~cm} \times 3 \mathrm{~cm}-5 \mathrm{~cm} \times 4 \mathrm{~cm}$ & - & \\
\hline Size of dead cavity (range) & $3 \mathrm{~cm} \times 3 \mathrm{~cm}-5 \mathrm{~cm} \times 4 \mathrm{~cm}$ & $3 \mathrm{~cm} \times 3 \mathrm{~cm}-5 \mathrm{~cm} \times 4 \mathrm{~cm}$ & 0.34 \\
\hline
\end{tabular}


Table 2 Comparison of indicators in the recovery period between the chimeric group and classical groups

\begin{tabular}{llll}
\hline Indicators & & $\begin{array}{l}\text { Chimeric group } \\
(n=26)\end{array}$ & $\begin{array}{l}\text { Classical group } \\
(n=25)\end{array}$ \\
\hline $\begin{array}{l}\text { Submandibular wound infection } \\
\text { (rate) }\end{array}$ & A & $4 / 26$ & $5 / 25$ \\
& B & 0 & $3 / 25$ \\
Wound healing time & C & 0 & $2 / 25$ \\
(days) & & $12.20 \pm 2.69$ & $15.67 \pm 4.09$ \\
$\begin{array}{l}\text { Flap operation time } \\
\text { (min) }\end{array}$ & & \\
Flap survival rate & $99.12 \pm 28.30$ & $96.71 \pm 20.64$ \\
$\quad$ Success & & \\
$\quad$ Partial loss & & $26 / 26$ & $0.0054^{*}$ \\
\hline
\end{tabular}

A: submandibular wound skin redness and edema; B: submandibular wound skin redness with a fluctuant swelling; C: sub oral fistula. Data presented as mean \pm $\mathrm{SD}$ or $\mathrm{n} / \mathrm{n}$, unless otherwise indicated. *Statistically significant difference

\section{Postoperative complications and recovery time}

Since submandibular infection is the main postoperative complication of this type of surgery, it was compared between the two treatment groups. Among the 26 patients in the chimeric group, 4 cases experienced submandibular skin redness and edema. Early interventions, including local drainage, compression bandage, and antibiotics treatment, were performed to promote healing. The other 22 patients healed in the first stage. The rate of the submandibular infection was $15.4 \%$.

Among the 25 patients in the classical group, 5 cases experienced submandibular skin redness and edema. Three cases also had fluctuant swelling in the submandibular region. Two cases developed submandibular fistula. Treatment with antibiotics, local effective drainage, and compression bandage were used for these 10 cases. The two patients with submandibular fistula were treated with a second operation for intraoral and wound debridement and closure. In total, 10 cases developed submandibular infection (40\%). There was a significant difference between the chimeric and classical groups in terms of the rate of submandibular infection $(P=0.025)$.

The recovery time from the first surgical procedure to rehabilitation was $12.20 \pm 2.69$ days for the chimeric group and $15.67 \pm 4.09$ days for the classical group. This difference was statistically significant $(P=0.0054)$.

Our findings indicate that the chimeric ALT flap can significantly reduce the incidence of submandibular wound infection and shorten the duration of wound healing.

\section{Risk factors for wound infection}

To identify risk factors for wound infection, a univariate analysis of risk factors was performed. The results showed statistically significant differences for the risk factors of smoking, betel nut consumption, diabetes, high blood pressure (HBP), and type of flap between the infection and non-infection groups $(P<0.05)$ (Table 3$)$.
We then analyzed the correlation of these factors with wound infection using multivariate logistic regression analysis. The results showed that the risk factors for wound infection were HBP (odds ratio $[\mathrm{OR}]=34.048 ; 95 \% \mathrm{CI}$ (2.051-565.264); $P=0.014)$, and type of flaps (OR= 19.258; 95\% CI (1.940-191.150); $P=0.012$ ) (Table 4).

\section{Submandibular appearance}

We evaluated the appearance of the submandibular region after surgery by measuring the angle between $\mathrm{Sn}$ Pos and Mes-K in lateral profile photos (Fig. 3a). The results were statistically evaluated and compared between the two groups. The angle of the chimeric group was $70.19 \pm 2.304$, while that of the classical group was $72.00 \pm 3.072$. There was a significant difference between the two groups $(P=0.0236)$ (Fig. 3b, c).

\section{Donor site function and quality of life post-operation}

The Lower Extremity Functional Scale (LEFS) [20] was used to assess the 51 patients six months after the operation (Additional file 1). The results were statistically evaluated. The LEFS score was $68.28 \pm 2.95$ in the chimeric group and $68.89 \pm 2.30$ in the classical group, and there was no statistical difference $(P=0.483)$. These findings showed that the function of the donor site was not significantly affected in the group treated with the chimeric ALT perforator flap (Fig. 4).

A UW-QOL questionnaire [21] was used to assess the patients six months after the operation (Additional file 2). The results showed that the value of mastication in the chimeric group was higher than that in the classical group $(P=0.032)$. The other items were similar between the two groups (Table 5).

\section{Discussion}

In this retrospective cohort study, we compared the postoperative outcome and complications between the patients reconstructed with the classical ALT perforator 
Table 3 Univariate analysis of the risk factors for wound infection

\begin{tabular}{|c|c|c|c|c|}
\hline \multirow[b]{2}{*}{ Variables } & \multicolumn{4}{|l|}{ Groups } \\
\hline & Infection & Non-infection & $x^{2}$ & $P$ \\
\hline Age (years) & & & 1.902 & 0.1679 \\
\hline$<50$ & 1 & 9 & & \\
\hline$>50$ & 13 & 28 & & \\
\hline Tumor stage & & & 2.949 & 0.0859 \\
\hline $\mathrm{T} 1-\mathrm{T} 2$ & 11 & 35 & & \\
\hline T3-T4 & 3 & 2 & & \\
\hline Nodal stage & & & 0.559 & 0.4547 \\
\hline No-N1 & 10 & 30 & & \\
\hline N2-N3 & 4 & 7 & & \\
\hline Clinical stage & & & 1.131 & 0.2876 \\
\hline$|-| \mid$ & 6 & 22 & & \\
\hline III-IV & 8 & 15 & & \\
\hline Cigarette & & & 3.996 & $0.0456^{*}$ \\
\hline No & 1 & 13 & & \\
\hline Yes & 13 & 24 & & \\
\hline Alcohol & & & 2.695 & 0.1006 \\
\hline No & 3 & 2 & & \\
\hline Yes & 11 & 35 & & \\
\hline Betel nut & & & 4.135 & $0.0420^{*}$ \\
\hline No & 0 & 9 & & \\
\hline Yes & 14 & 28 & & \\
\hline Diabetes & & & 4.006 & $0.0453^{*}$ \\
\hline No & 8 & 31 & & \\
\hline Yes & 6 & 6 & & \\
\hline HBP & & & 5.251 & $0.0219^{*}$ \\
\hline No & 10 & 35 & & \\
\hline Yes & 4 & 2 & & \\
\hline Type of flaps & & & 3.878 & $0.0489^{*}$ \\
\hline Chimeric flap & 4 & 22 & & \\
\hline Classical flap & 10 & 15 & & \\
\hline
\end{tabular}

The chi-square test was used. $P<0.05$ was considered to be statistically significant. $H B P$ high blood pressure. *Statistically significant difference

Table 4 Multivariate logistic regression analysis for the risk factors of wound infection

\begin{tabular}{llll}
\hline Variables & Wals & OR $(95 \% \mathrm{Cl})$ & $P$ \\
\hline cigarette & - & - & NS \\
Betel nut & - & - & NS \\
Diabetes & - & - & NS \\
HBP & 6.057 & $34.048(2.051-565.264)$ & $0.014^{*}$ \\
Type of flaps & 6.381 & $19.258(1.940-191.150)$ & $0.012^{*}$ \\
\hline $\begin{array}{l}P<0.05 \text { was considered to be statistically significant. } \text { HBP high blood pressure. } \\
\text { *Statistically significant difference }\end{array}$
\end{tabular}

flap and the patients reconstructed with a chimeric ALT perforator flap with vastus lateralis muscle mass. The results showed that the infection rate was reduced and the submandibular fullness was satisfactory in the chimeric group.

The process of lymphatic drainage of tongue tissue is rich and complex [1]. Lymphatic fluid first concentrates in the floor of the mouth and is then transferred into the upper cervical lymph nodes [2]. Tumor cells move downwards, along the path of least resistance [22]. The metastasis of the lymph nodes of the floor of the mouth is difficult to observe and diagnose [4]. As a result, it has been proposed that the radical dissection of tongue cancer should contain both the primary lesions and possible pathways of metastasis, including the partial suprahyoid muscle groups and the lymphatic, neurovascular, and glandular tissues $[5,7,8]$. In this study, we resected the primary lesions and partial suprahyoid muscle groups in all cases. However, as a result, an extensive empty space in the floor of the mouth and submandibular region was left.

The reconstruction of both the primary site and the floor of the mouth for tongue cancer patients is a challenge for surgeons. The anterolateral thigh flap (ALT) has been used for reconstruction in tongue cancer patients for several decades $[8,12,13]$. However, perforators are not dissected through vastus lateralis muscle in the traditional ALT flap and thus the muscle and overlying skin are generally harvested as a single, large section $[12,13]$. Because of the poor flexibility of the traditional ALT flap, the shape of the reconstructed tongue is generally unsatisfactory. In this study, the perforator was dissected through the muscle, and the vastus lateralis muscle component was carried in the distal runoff of the descending branch of LCFA in the chimeric group [23]. We found that the chimeric perforator ALT flap with a muscle component was suitable for most cases of tongue cancer, with the following advantages: (1) The damage of donor site is reduced as much as possible because both the flap and muscle component are harvested precisely according to the size of oral and submandibular defects, which obeys the principle of "economy of donor site incisions" [16, 24]; (2) The distance between the perforator of the flap and the muscle component is about 3-5 cm, which provides a greater degree of freedom to inset the muscle mass $[23,25]$.

The perforator-based chimeric flap has been used in the reconstruction of extensive extremity defects with a deep and slender dead space [23]. Recently, it has also been used in complex or multiple defects in the head and neck region [26]. For example, Lai et al. [27] used the chimeric ALT flap to reconstruct the complete loss of upper and lower lips. Zeng et al. [28] used the 


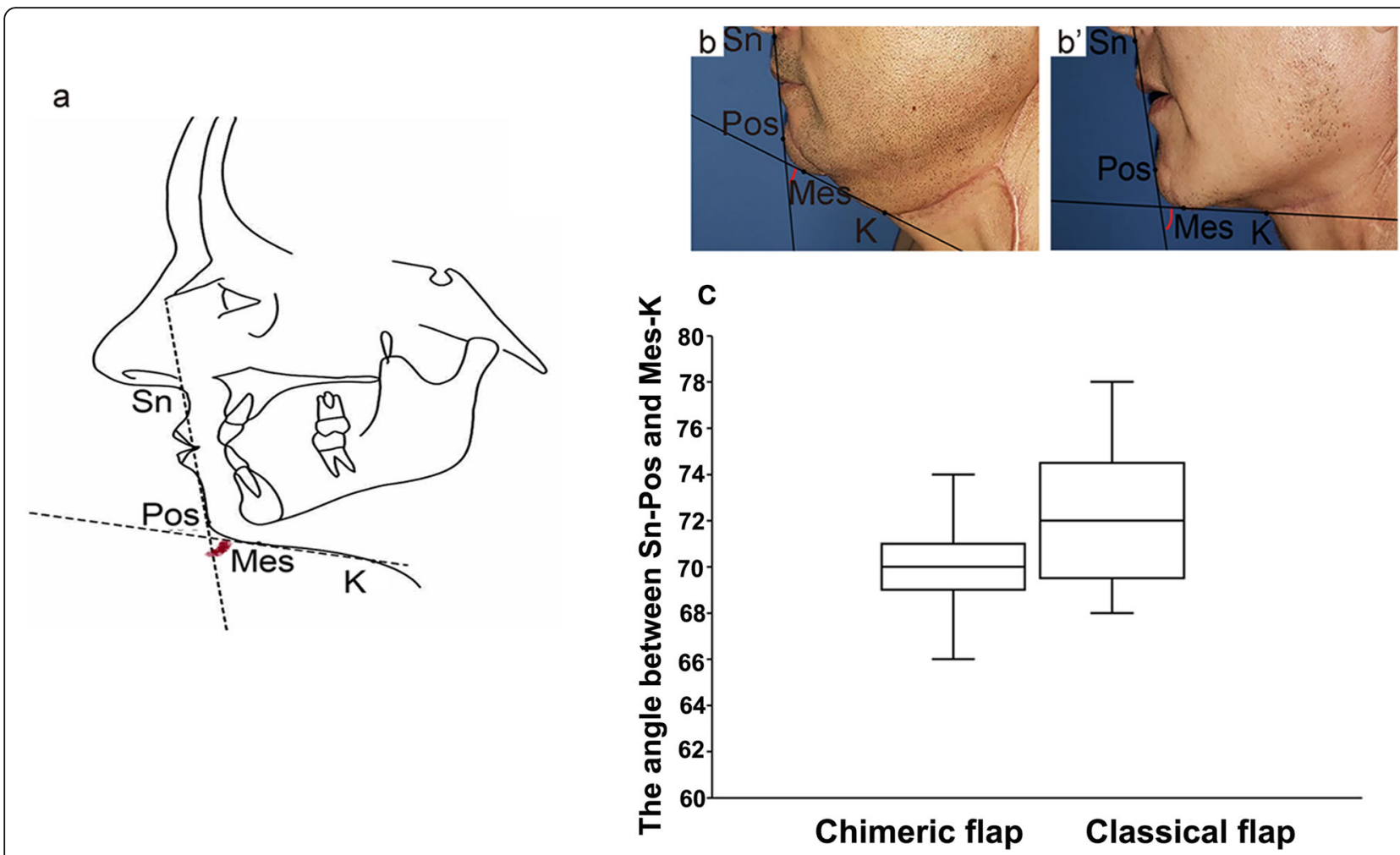

Fig. 3 Comparison of submandibular appearance between the two treatment groups. a Assessment of submandibular appearance by measuring the angle between Sn-Pos and K-Pos. b Submandibular appearance of tongue cancer patients after chimeric ALT perforator flap reconstruction. b' Submandibular appearance of tongue cancer patients after classical ALT perforator flap reconstruction. c Statistical results of the comparison between the two groups

chimeric ALT perforator flap to reconstruct the complex total parotidectomy defect. Jiang et al. [29] used multipaddled ALT flaps to reconstruct multiple oral defects. However, this study is the first to report on the application of the chimeric ALT perforator flap with a muscle component after the radical resection of tongue cancer. We found that the chimeric ALT perforator flap could be used to significantly reduce the incidence of wound infection, shorten the time of wound healing, and obtain a better submandibular appearance.

In this retrospective study, the factors of HBP and the types of flap used were found to have a significant effect on the rate of wound infection, using both univariate and multivariate analyses. However, other risk factors, including smoking, betel nut consumption, and diabetes, were only found to be significant in the univariate

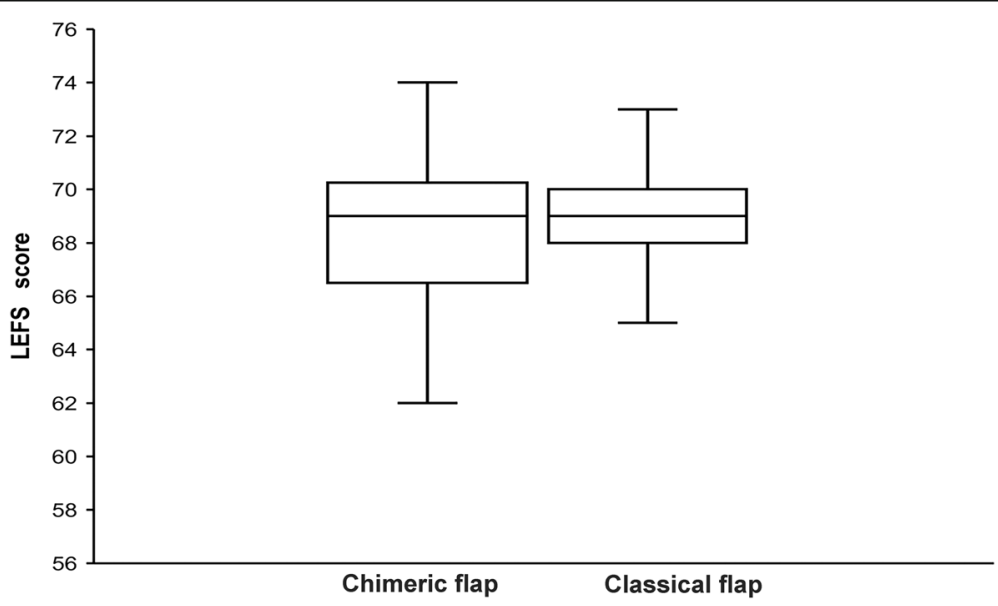

Fig. 4 Bar graph illustrating the differences in LEFS between the two groups treated with chimeric and classical flaps 
Table 5 Comparison of UW-QOL scores between the chimeric group and classical groups

\begin{tabular}{llll}
\hline Indicators & Chimeric group & Classical group & $P$ \\
\hline Pain & $70.65 \pm 25.22$ & $69.60 \pm 25.77$ & 0.89 \\
Activity & $66.15 \pm 19.32$ & $63.00 \pm 20.49$ & 0.67 \\
Recreation & $64.42 \pm 23.18$ & $61.80 \pm 24.85$ & 0.70 \\
Swallowing & $63.65 \pm 22.26$ & $54.40 \pm 23.04$ & 0.16 \\
Chewing & $66.92 \pm 18.76$ & $54.60 \pm 20.39$ & $0.032^{*}$ \\
Speech & $55.77 \pm 18.33$ & $55.00 \pm 19.90$ & 0.88 \\
Shoulder & $67.88 \pm 21.67$ & $69.80 \pm 17.63$ & 0.74 \\
Taste & $62.12 \pm 22.37$ & $57.60 \pm 21.73$ & 0.48 \\
Saliva & $57.88 \pm 20.29$ & $56.80 \pm 23.15$ & 0.86 \\
Mood & $61.73 \pm 25.94$ & $60.80 \pm 22.26$ & 0.89 \\
Anxiety & $59.62 \pm 21.26$ & $57.80 \pm 18.55$ & 0.75 \\
\hline
\end{tabular}

*Statistically significant difference

analysis, and not in the multivariate analysis, which may result from an insufficient sample size. Therefore, a prospective case-control study with a larger sample size will be needed to verify our findings.

\section{Conclusion}

The chimerical ALT perforator flap with vastus lateralis muscle mass can be used to accurately and safely reconstruct both oral and submandibular defects. This type of perforator flap maintains the profile and fullness of the submandibular region and may reduce the incidence of submandibular infection.

\section{Supplementary information}

Supplementary information accompanies this paper at https://doi.org/10. 1186/s12903-020-01066-X.

Additional file 1. Lower Extremity Functional Scale (LEFS).

Additional file 2. University of Washington Quality of Life Questionnaire.

\section{Abbreviations}

ALT: Anterolateral thigh cutaneous; OSCC: Oral squamous cell carcinoma; LEFS: The Lower Extremity Functional Scale; UW-QOL: The University of Washington quality of Life questionnaire; TNM: Tumor, node, metastasis; LCFA: Lateral circumflex femoral artery; HBP: High blood pressure

\section{Acknowledgements}

Not applicable.

\section{Authors' contributions}

Guided the study: FG. Wrote the manuscript: RY, XSW, FG. Collected and analyzed the data: RY, XSW, PAK. Designed the study: YFX, CHJ, XCJ. All authors read and approved the final manuscript.

\section{Funding}

This research did not receive any specific grant from funding agencies in the public, commercial or non-profit sectors.

\section{Availability of data and materials}

The data sets used and/or analyzed in this study are available from the corresponding author upon reasonable request.

\section{Ethics approval and consent to participate}

Ethical approval for this study was obtained from the Medical Ethics Committee of Xiangya Hospital, Central South University (no. 201910412).

The study adhered to the Declaration of Helsinki. The administrative permissions were acquired by Dr. Guo's team to access the data used in this research. The patient data was de-identified.

\section{Consent for publication}

All the patients gave their written informed consent to participate in this study. The consent for the publication of identifying images was obtained from the patient.

\section{Competing interests}

The authors declare that they have no competing interests.

Received: 22 October 2019 Accepted: 6 March 2020

Published online: 30 March 2020

\section{References}

1. Prince S, Bailey BM. Squamous carcinoma of the tongue: review. Br J Oral Maxillofac Surg. 1999;37:164-74.

2. Ando M, Asai M, Asakage T, Oyama W, Saikawa M, Yamazaki M, Miyazaki M, Ugumori T, Daiko H, Hayashi R. Metastatic neck disease beyond the limits of a neck dissection: attention to the 'Para-hyoid' area in T1/2 oral tongue cancer. Jpn J Clin Oncol. 2009:39:231-6.

3. Bleyer A. Cancer of the oral cavity and pharynx in young females: increasing incidence, role of human papilloma virus, and lack of survival improvement. Semin Oncol. 2009;36:451-9.

4. Z Zhang T, Ord RA, Wei WI, Zhao J. Sublingual lymph node metastasis of early tongue cancer: report of two cases and review of the literature. Int J Oral Maxillofac Surg. 2011:40:597-600

5. Calabrese L, Bruschini R, Giugliano G, Ostuni A, Maffini F, Massaro MA, Santoro L, Navach L, Preda L, Alterio D, Ansarin M, Chiesa F. Compartmental tongue surgery: long term oncologic results in the treatment of tongue cancer. Oral Oncol. 2011;47:174-9.

6. Steinhart $\mathrm{H}$, Kleinsasser $\mathrm{O}$. Growth and spread of squamous cell carcinoma of the floor of the mouth. Eur Arch Otorhinolaryngol. 1993;250:358-61.

7. Tagliabue M, Gandini S, Maffini F, Navach V, Bruschini R, Giugliano G, Lombardi F, Chiocca S, Rebecchi E, Sica E, Tommasino M, Calabrese L, Ansarin L. The role of the T-N tract in advanced stage tongue cancer. Head Neck. 2019;41:1-12.

8. Calabrese L, Giugliano G, Bruschini R, Ansarin R, Navach V, Grosso E, Gibelli $B$, Ostuni A, Chiesa F. Compartmental surgery in tongue tumors: description of a new surgical technique. Acta Otorhinolaryngol Ital. 2009;29:259-64.

9. Dutton JM, Graham SM, Hoffman HT. Metastatic cancer to the floor of mouth: the lingual lymph nodes. Head Neck. 2002;24:401-5.

10. Chang WC, Chang CF, Cheng CM, Yang CY, Chen YW. Comparison of the hospitalization period after microvascular reconstruction flap in trismus patients: free anterolateral thigh flap versus free forearm flap. Clin Oral Investig. 2019;23:2951-7

11. Cherubino M, Turri-Zanoni BP, Giudice M, Pellegatta I, Tamborini F, Guzzetti L, Di Giovanna D, Bignami M, Calati C, Castelnuovo P, Valdatta L. Chimeric anterolateral thigh free flap for reconstruction of complex cranio-orbitofacial defects after skull base cancers resection. J Craniomaxillofac Surg. 2017:45:87-92.

12. Song $Y G$, Chen $G Z$, Song $Y L$. The free thigh flap: a new free flap concept based on the septocutaneous artery. Br J Plast Surg. 1984;37:149-59.

13. Chana JS, Odili J. Perforator flaps in head and neck reconstruction. Semin Plast Surg. 2010;24:237-54

14. Tong XJ, Tang ZG, Shan ZF, Guo XC. The anterolateral thigh flap for soft tissue reconstruction in patients with tongue squamous cell carcinoma. World J Surg Oncol. 2016:14:213-9.

15. Sun G, Lu M, Hu Q, Hu Q, Tang E, Yang X, Wang Z. Clinical application of thin anterolateral thigh flap in the reconstruction of intraoral defects. Oral Surg Oral Med Oral Pathol Oral Radiol. 2013;115:185-91. 
16. Zhang YX, Hayakawa TJ, Levin LS, Hallock GG, Lazzeri D. The Economy in Autologous Tissue Transfer: Part 1. The Kiss Flap Technique. Plast Reconstr Surg. 2016;137:1018-30.

17. Lydiatt WM, Patel SG, Osullivan B, et al. Head and neck cancers-major changes in the American joint committee on cancer eighth edition cancer staging manual. CA-A Cancer J Clin. 2017;67:122-37.

18. Guo F, Min AJ, Jiang CH, Jian XC, Chen XQ, Su T, Tang ZG. Reconstruction of oral and maxillofacial defects using free anterolateral thigh flaps in patients with malignant tumors. Shanghai Kou Qiang Yi Xue. 2011;20:62-5.

19. Gupta A, Lakhiani C, Lim BH, Aho JM, Goodwin A, Tregaskiss A, Lee M, Scheker L, Saint-Cyr M. Free tissue transfer to the traumatized upper extremity: risk factors for postoperative complications in 282 cases. J Plast Reconstr Aesthet Surg. 2015;68:1184-90.

20. Binkley JM, Stratford PW, Lott SA, Riddle DL. The lower extremity functional scale (LEFS): scale development, measurement properties, and clinical application. North American Orthopaedic rehabilitation research network. Phys Ther. 1999;79:371-83.

21. Laraway DC, Rogers SN. A structured review of journal articles reporting outcomes using the University of Washington Quality of life scale. Br J Oral Maxillofac Surg. 2012;50:122-31.

22. De Wever O, Mareel M. Role of tissue stroma in cancer cell invasion. J Pathol. 2003:200:429-47.

23. Lin YT, Lin CH, Wei FC. More degrees of freedom by using chimeric concept in the applications of anterolateral thigh flap. J Plast Reconstr Aesthet Surg. 2006;59:622-7.

24. Qing $L M$, Wu PF, Yu F, Zhou Z, Tang J. Use of a sequential chimeric perforator flap for one-stage reconstruction of complex soft tissue defects of the extremities. Microsurgery. 2019;22:1-8.

25. Kim JT, Kim YH, Ghanem AM. Perforator chimerism for the reconstruction of complex defects: a new chimeric free flap classification system. J Plast Reconstr Aesthet Surg. 2015;68:1556-67.

26. Wu K, Ji T, Cao W, Wu HJ, Ren ZH. Application of a new classification of chimeric anterolateral thigh free flaps. J Craniomaxillofac Surg. 2019;47: 1198-202.

27. Lai CL, Ou KW, Chen SG, Chen TM, Li HP, Chang SC. Reconstruction of the complete loss of upper and lower lips with a chimeric anterolateral thigh flap: a case report. Microsurgery. 2012;32:30-63.

28. Zeng L, Jiang CH, Li N, Liu W, Wang F, Guo F. Vascularized fascia lata for prevention of postoperative parotid fistula arising from partial parotidectomy during neck dissection. J Oral Maxillofac Surg. 2017;75: 1071-80.

29. Jiang CH, Guo F, Li N, Liu W, Su T, Chen XQ, Zheng L, Jian XC. Multipaddled anterolateral thigh chimeric flap for reconstruction of complex defects in head and neck. PLoS One. 2014:9:e106326.

\section{Publisher's Note}

Springer Nature remains neutral with regard to jurisdictional claims in published maps and institutional affiliations.

Ready to submit your research? Choose BMC and benefit from:

- fast, convenient online submission

- thorough peer review by experienced researchers in your field

- rapid publication on acceptance

- support for research data, including large and complex data types

- gold Open Access which fosters wider collaboration and increased citations

- maximum visibility for your research: over $100 \mathrm{M}$ website views per year

At $\mathrm{BMC}$, research is always in progress.

Learn more biomedcentral.com/submissions 